\title{
Effects of fatty acid synthase inhibitors on lymphatic vessels: an in vitro and in vivo study in a melanoma model
}

\author{
Débora C Bastos ${ }^{1}$, Jenny Paupert ${ }^{2}$, Catherine Maillard², Fabiana Seguin ${ }^{1}$, Marco A Carvalho ${ }^{1}$, Michelle Agostini ${ }^{1}$, \\ Ricardo D Coletta ${ }^{1}$, Agnès Noël ${ }^{2}$ and Edgard Graner ${ }^{1}$
}

Fatty acid synthase (FASN) is responsible for the endogenous production of fatty acids from acetyl-CoA and malonyl-CoA. Its overexpression is associated with poor prognosis in human cancers including melanomas. Our group has previously shown that the inhibition of FASN with orlistat reduces spontaneous lymphatic metastasis in experimental B16-F10 melanomas, which is a consequence, at least in part, of the reduction of proliferation and induction of apoptosis. Here, we sought to investigate the effects of pharmacological FASN inhibition on lymphatic vessels by using cell culture and mouse models. The effects of FASN inhibitors cerulenin and orlistat on the proliferation, apoptosis, and migration of human lymphatic endothelial cells (HDLEC) were evaluated with in vitro models. The lymphatic outgrowth was evaluated by using a murine ex vivo assay. B16-F10 melanomas and surgical wounds were produced in the ears of C57BI/6 and Balb-C mice, respectively, and their peripheral lymphatic vessels evaluated by fluorescent microlymphangiography. The secretion of vascular endothelial growth factor C and D (VEGF-C and -D) by melanoma cells was evaluated by ELISA and conditioned media used to study in vitro lymphangiogenesis. Here, we show that cerulenin and orlistat decrease the viability,

proliferation, and migration of HDLEC cells. The volume of lymph node metastases from B16-F10 experimental melanomas was reduced by $39 \%$ in orlistat-treated animals as well as the expression of VEGF-C in these tissues. In addition, lymphatic vessels from orlistat-treated mice drained more efficiently the injected FITC-dextran. Orlistat and cerulenin reduced VEGFC secretion and, increase production of VEGF-D by B16-F10 and SK-Mel-25 melanoma cells. Finally, reduced lymphatic cell extensions, were observed following the treatment with conditioned medium from cerulenin- and orlistat-treated B16-F10 cells. Altogether, our results show that FASN inhibitors have anti-metastatic effects by acting on lymphatic endothelium and melanoma cells regardless the increase of lymphatic permeability promoted by orlistat.

Laboratory Investigation (2017) 97, 194-206; doi:10.1038/labinvest.2016.125; published online 5 December 2016

Human fatty acid synthase (FASN, EC2.3.1.85, 270-kDa) is the cytosolic enzyme that produces endogenous long-chain fatty acids from acetyl-CoA and malonyl-CoA. ${ }^{1}$ Physiologically, FASN is expressed in hormone-sensitive cells and cells with high lipid metabolism, ${ }^{2}$ however, in most normal cells, de novo fatty acid synthesis is rarely needed and therefore, FASN levels are usually low. Conversely, several human malignancies as well as some pre-neoplastic lesions show high FASN expression, ${ }^{3}$ which suggests its use as a prognostic marker. ${ }^{4-9}$ In fact, FASN was originally identified as the oncogenic antigen-519 (OA-519) in breast cancer patients with poor prognosis. ${ }^{10,11}$ The first experimental evidence of an oncogenic role for FASN came from its overexpression in HBL100 immortalized breast epithelial cells, which show increased proliferation and survival as well as anchorageindependent growth. ${ }^{12}$ Similarly, human prostate epithelial cells (iPrECs) overexpressing both FASN and androgen receptor become tumorigenic, suggesting that the former acts as an oncoprotein because of its anti-apoptotic effect. ${ }^{13}$ FASN pharmacological inhibitors decrease tumor cell proliferation, elicit tumor cell death, and prevent tumor growth in animal models. ${ }^{14}$ Orlistat is a pancreatic lipase inhibitor originally developed as an anti-obesity drug that irreversibly blocks FASN activity and shows anticancer properties. ${ }^{15}$ We have

${ }^{1}$ Department of Oral Diagnosis, School of Dentistry of Piracicaba, State University of Campinas (UNICAMP), Piracicaba, Brazil and ${ }^{2}$ Laboratory of Tumor and Development Biology, Groupe Interdisciplinaire de Génoprotéomique Appliqué-Cancer (GIGA-Cancer), University of Liège, Liège, Belgium

Correspondence: Dr E Graner, PhD, Department of Oral Diagnosis, School of Dentistry of Piracicaba, State University of Campinas (UNICAMP), Av. Limeira 901, CP 52, Areão, Piracicaba 13414-903, SP, Brazil.

E-mail: graner@unicamp.br

Received 19 April 2016; revised 4 October 2016; accepted 26 October 2016 
previously shown that FASN inhibition with orlistat significantly reduces the number of spontaneous mediastinal lymph node metastasis from intraperitoneal B16-F10 mouse melanomas. ${ }^{16}$ However, we have also demonstrated that orlistat reduces the proliferation and promotes apoptosis through activation of the intrinsic pathway in the same cells, independent of p53 or mitochondrial permeability transition. ${ }^{16,17}$ Furthermore, FASN inhibition with orlistat reduces both the proliferation of human blood vessel endothelial cells and neovascularization in an ex vivo assay, suggesting antiangiogenic abilities for this drug. ${ }^{18}$

Lymphatic vessels regulate tissue fluid homeostasis, immune cell trafficking, and the absorption of dietary fats. ${ }^{19,20}$ In adult tissues, lymphangiogenesis is observed during wound healing, tumor growth, and metastasis. ${ }^{21}$ Lymphatic circulation is the main route for metastasis in several malignancies, such as those from breast, pancreas, stomach, colon, head and neck, prostate, lung, and melanomas. ${ }^{22,23}$ Vascular endothelial growth factor (VEGF) family members and its receptors have a central role in angiogenesis and lymphangiogenesis in both physiological and pathological conditions. ${ }^{24}$ VEGF-C and -D have major roles in tumor lymphangiogenesis ${ }^{25,26}$ through the interaction with vascular endothelial growth factor receptor (VEGFR)-3 and VEGFR-2 (mainly associated with angiogenesis). ${ }^{27}$ In addition, co-receptors such as neuropilin-2 (NRP-2), post-translational cleavage of VEGF-C and -D, as well as VEGFR-2/VEGFR-3 heterodimerization are also involved in this process. ${ }^{27-29}$ In mouse models, VEGF-C and -D overexpression is associated with increased lymphatic vessel density and lymph node metastasis in different types of cancer. $^{30-34}$ Both factors were detected in several human malignancies, such as melanomas, adenocarcinomas of the lung, as well as breast, colon, head and neck, and gastric cancers. $^{22}$ However, the expression of VEGF-C, but not VEGF-D, has been correlated with lymph node metastasis in different types of cancers, including melanoma. ${ }^{27,34-36} \mathrm{Lymph}$ node metastases are important for tumor staging and therapeutic decisions, and the density of tumor-associated lymphatic vessels seems to correlate with the incidence of lymph node metastasis and poor prognosis in melanoma and other human malignancies. ${ }^{21,22,37,38}$ Moreover, the number and size of intratumoral lymphatic vessels is significantly higher in metastatic melanomas and correlated with poor disease-free and overall survival. ${ }^{39}$

The role of FASN on the lymphatic network and tumor-induced lymphangiogenesis is still unknown. Here, we provide the first evidence that FASN inhibitors differentially modulate VEGF-C and -D expression in mouse melanoma cells and act both on lymphatic endothelial cells and melanoma cells. We also demonstrate that orlistat affects the permeability of the lymphatic vasculature and reduces the size of lymph node metastasis in experimental melanomas.

\section{MATERIALS AND METHODS Cell Culture}

B16-F10 mouse melanoma cells and SK-Mel-25 human melanoma cells (ATCC, Manassas, VA, USA) were maintained in RPMI (Invitrogen, Camarillo, CA, USA) with 1 or $10 \%$ of fetal bovine serum (FBS, Cultilab, Campinas, Brazil). Human oral squamous carcinoma cells (SCC-9, ATCC) were grown in DMEM/F-12 (Invitrogen) with 10\% FBS and $400 \mathrm{ng} / \mathrm{ml}$ hydrocortisone. hTERT-HDLEC human lymphatic endothelial cells $^{40}$ were cultured in Endothelial Basal Medium-2 (EBM-2, Lonza, Walkersville, MD, USA) supplemented with single quots (Lonza), 5\% of FBS, and 1:500 penicillin-streptomycin (Invitrogen). Primary human dermal lymphatic endothelial cells (HDLEC, Promocell, Heidelberg, Germany) were cultured in endothelial cell growth medium MV2 (Promocell). Cells were cultured with or without antibiotic/antimycotic solution (Invitrogen) at $37^{\circ} \mathrm{C}$ in humidified atmosphere with $5 \% \mathrm{CO}_{2}$. Orlistat (Roche, Basel, Switzerland) was prepared as described elsewhere ${ }^{41}$ and cerulenin (Sigma-Aldrich, St Louis, MO, USA) used at the concentrations described in the figure legends.

\section{Cell Viability, Proliferation, and Apoptosis}

Cell viability was determined by seeding $2 \times 10^{5}$ HDLEC cells in 6-well culture plates with 3(4,5-dimethylthiazol-2-yl)-2,5 diphenyltetrazolium bromide (MTT, Sigma) according to the manufacturer's instructions. For the study of cell cycle and apoptosis, HDLEC cells $\left(4 \times 10^{5}\right)$ were seeded in T-25 culture flasks and serum starved for $24 \mathrm{~h}$ (cell cycle only). The medium was replaced by fresh medium containing FASN inhibitors and HDLEC cells incubated for additional $24 \mathrm{~h}$, collected and cell cycle or apoptosis analyzed as previously described. ${ }^{17}$ All experiments were performed at least three times independently.

\section{Spheroid Assay}

The in vitro lymphangiogenesis assay with spheroids was performed as described by Detry et al. ${ }^{42}$ Spheroids were generated by seeding $2 \times 10^{3}$ hTERT-HDLEC cells in each well of 96-well non-adherent culture plates with round bottom (Greiner, Frickenhausen, Germany) in reduced EBM-2 medium (without growth factors) containing 1\% of FBS and $0.24 \%$ of high viscosity methylcellulose (Sigma). After $24 \mathrm{~h}$ at $37^{\circ} \mathrm{C}$ and $5 \% \mathrm{CO}_{2}$, cells from each well formed spheroids that were collected and embedded into $600 \mu \mathrm{l}$ of collagen gels. Type I collagen from rat tail (BD Biosciences, San Jose, CA, USA) was prepared according to the manufacturer and mixed 1:1 with $1.2 \%$ methylcellulose dissolved in reduced medium. Spheroids were then seeded in 24 well plates and incubated at $37^{\circ} \mathrm{C}$ in $5 \% \mathrm{CO}_{2}$. FASN inhibitors were added in both collagen gels and cell culture media. Conditioned medium obtained from B16-F10 cells treated or not with cerulenin or orlistat was also used to incubate the spheroids. After $24 \mathrm{~h}$, the spheroid sprouting/ migration was visualized and photographed in a phase- 
contrast microscope (Leica Microsystems, Wetzlar, Germany). The number of cells that migrate from each spheroid and the filopodia-like cell extensions were counted with the aid of the Scion Image software (Scion Corporation, Frederick, MD, USA).

\section{Lymphatic Ring Assay}

Tridimensional primary cultures of mouse lymphatic endothelial cells were performed according to Bruyère et al. ${ }^{43}$ Thoracic ducts were removed from female C57Bl/6 mice with 4-8 weeks of age by microsurgery and cut into $1 \mathrm{~mm}$ pieces. The explants were embedded between two layers of type I collagen $(2 \mathrm{mg} / \mathrm{ml}$, Serva Electrophoresis, Heidelberg, Germany) and cultured for 11 days in MCDB-131 (Invitrogen) supplemented with $4 \%$ Ultroser G (BioSepra, Northborough, MA, USA), $25 \mathrm{mM}$ of $\mathrm{NaHCO}_{3}, 1 \%$ of glutamine, $100 \mathrm{U} / \mathrm{ml}$ of penicillin, and $100 \mathrm{mg} / \mathrm{ml}$ of streptomycin. Cultures were maintained at $37^{\circ} \mathrm{C}$ in a humidified incubator (HERAcell 150, Heraeus, Hanau, Germany) under reduced oxygen condition $\left(5 \% \mathrm{O}_{2}, 5 \% \mathrm{CO}_{2}\right.$, and $\left.90 \% \mathrm{~N}_{2}\right)$. The rings were photographed each 2 days and the image analyses performed at day 10 . On day 11 , lymphatic rings were collected, washed for $30 \mathrm{~min}$ in PBS, fixed for $30 \mathrm{~min}$ with $70 \%$ ethanol and used for alpha smooth muscle actin $(\alpha-$ SMA) whole mount immunostaining. Rings negative for $\alpha$ SMA were used for quantification, which was performed by generating a grid of concentric circles by successive increments at fixed intervals from the thoracic duct boundary. The number of microvessel-grid intersections was counted and plotted according to the distance from the ring. At least five images for each experimental condition were used and the values obtained from 0.15 to $0.75 \mathrm{~mm}$ in the control and treated explants compared. All experiments were approved by the Committee for Ethics in Animal Research of the State University of Campinas (1934-1).

\section{Protein Extraction and Western Blotting}

Protein lysates from cells or experimental melanomas and western blotting reactions were done as previously described ${ }^{16}$ with antibodies against FASN (Transduction Laboratories, Lexington, KY, USA) diluted at 1:3000. Antibodies against $\beta$ actin (Sigma, 1:30 000) were used as the loading control.

\section{Immunofluorescence for VEGFR-3}

Orlistat- or cerulenin-treated HDLEC cells were stained with anti-VEGFR-3 antibodies (Reliatech). HDLEC cells $\left(1 \times 10^{6}\right)$ were seeded in $150 \mathrm{~mm}$ culture dishes and after $24 \mathrm{~h}$ treated with orlistat or cerulenin for additional $24 \mathrm{~h}$. Then, cells were collected by scraping with cell-spatulas in cold PBS. The cell suspension was fixed in 70\% ETOH for $15 \mathrm{~min}$, washed with PBS, blocked with $1 \% \mathrm{PBS} / \mathrm{BSA}$, and incubated with antibodies against VEGFR-3 (1:100) for $1 \mathrm{~h}$ at room temperature. After another washing step, cells were incubated with FITC-anti-rat antibodies (1:250, Vector Laboratories, Burlingame, CA, USA) for $1 \mathrm{~h}$ and, after further washing, cell suspensions analyzed in a FACSCalibur flow cytometer equipped with an argon laser and CellQuest software (Becton Dickinson, Bedford, MA).

\section{Animal Experiments and Microlymphangiography}

The animal studies were approved by the Committee for Ethics in Animal Research of the State University of Campinas (1333-1). For the hole punch assay, Balb-C mice were anesthetized with ketamine/xylazine $(10 / 100 \mathrm{mg} / \mathrm{kg}$ i.p.) and a hole (1.5 mm of diameter) made in the center of both ears by using a metal ear punch. The animals were treated for 25 days with i.p. injections of orlistat (Roche, $240 \mathrm{mg} / \mathrm{kg}$ ) or the equivalent amount of vehicle ( $33 \%$ ethanol in PBS) according to Kridel et $a l^{15}$ and killed by cervical dislocation. For the analysis of peritumoral lymphatics, primary tumors, and lymph node metastases, $10^{5} \mathrm{~B} 16$-F10 cells resuspended in $5 \mu \mathrm{l}$ of PBS were injected intradermally in each ear of $\mathrm{C} 57 \mathrm{Bl} / 6$ mice with $5-8$ weeks of age. $\mathrm{C} 57 \mathrm{Bl} / 6$ mice without surgical wounds or melanomas were also treated and killed as described above. The number of animals and experimental groups is shown in Supplementary Table 1. Functional lymphatics were visualized as described elsewhere, ${ }^{44}$ after the injection of $2 \mu \mathrm{l}$ of lysine-fixable FITC-dextran $(2000 \mathrm{kDa}$, Molecular Probes, Eugene, OR, USA). Photomicrographies were performed in a Leica DMR microscope with epifluorescence (Leica Microsystems) and images with identical conditions of light, contrast, and magnification used for the analysis with the Scion Image software (Scion Corporation). The lines drawn along the lymphatic trajectory were measured in pixels and converted in millimeters according to the image size. Metastatic superficial cervical lymph nodes were blackened and therefore easily detected and collected. Previous studies demonstrated that Evan's blue or fluorescence auricular lymphangiography revealed a dense auricular network of lymphatic capillaries, draining to a larger vessel at the ear base and subsequently to the superficial cervical lymph nodes. ${ }^{44}$ The volumes of the primary tumors and metastatic lymph nodes were calculated by using the formula volume $=$ width $^{2}(\mathrm{~mm}) \times$ length $(\mathrm{mm}) / 2$. Samples of the primary tumors, lymph nodes, and livers were collected and immediately frozen in liquid nitrogen for total RNA and protein extractions or Oil red O staining. ${ }^{45}$ Experiments were made three times independently.

\section{Quantitative RT-PCR}

Total RNA was extracted from tumor tissues or cell pellets using the Trizol reagent (Invitrogen) according to the manufacturer's instructions. RNA samples were treated with $1 \mathrm{U}$ of DNAse I (amplification grade, Invitrogen) for $10 \mathrm{~min}$ at room temperature to eliminate genomic DNA contamination. cDNAs were synthesized from 1 to $3 \mu \mathrm{g}$ of total RNA using the First-Strand cDNA Synthesis SuperScripT II RT (Invitrogen). Quantitative RT-PCR was conducted using SYBR Green Real-time PCR Master Mix (Applied Biosystems, Warrington, UK). The cycling conditions were $95^{\circ} \mathrm{C}$ for 

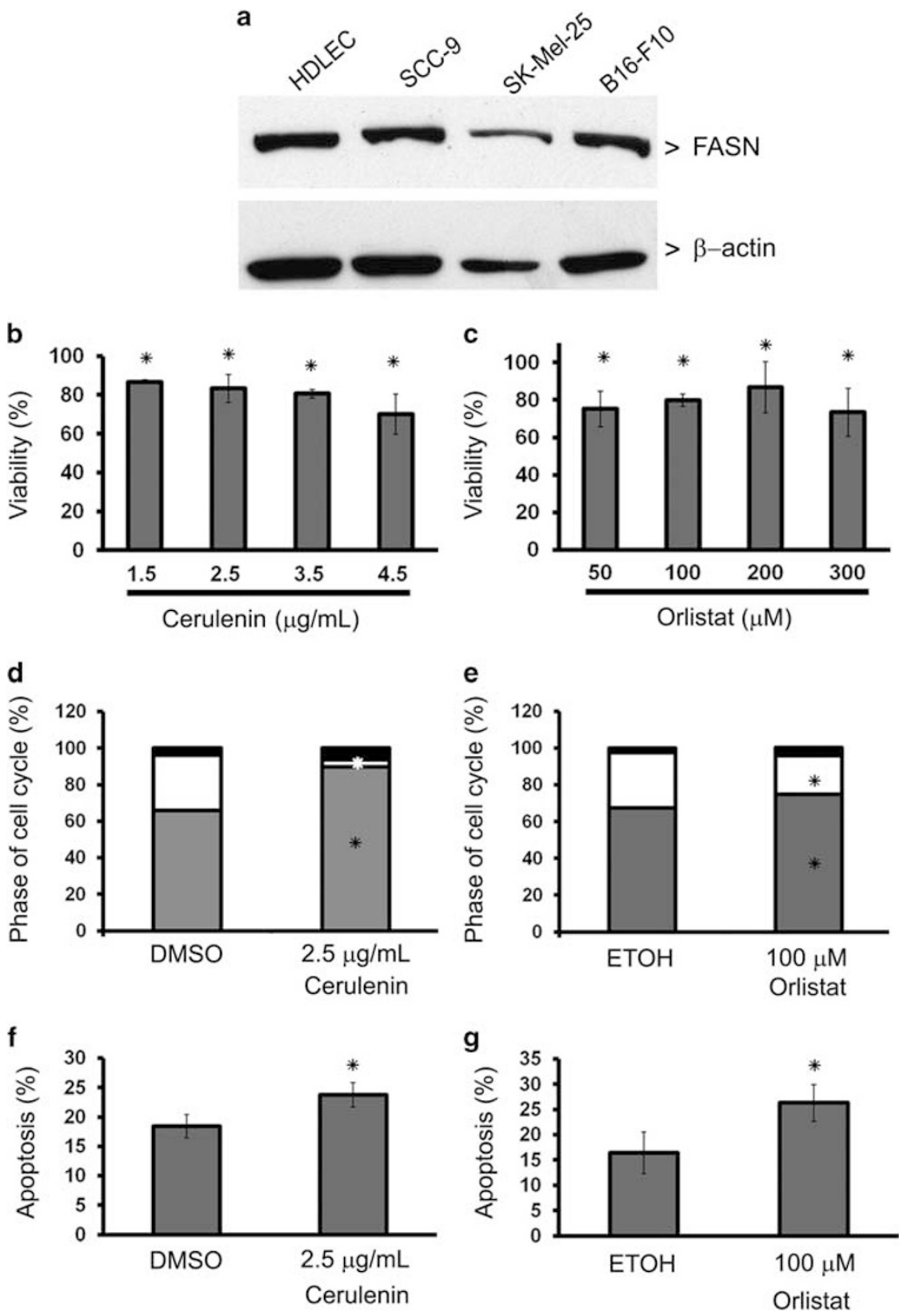

Figure 1 Fatty acid synthase (FASN) inhibitors reduce proliferation and promote apoptosis in human lymphatic endothelial cells (HDLEC) cells. (a) Total protein lysates were analyzed by western blotting and show that HDLEC cells, similarly to melanoma (SK-Mel-25 and B16-F10) and oral squamous carcinoma cells (SCC-9), are high FASN producers. The viability of HDLEC cells was reduced in all tested concentrations of cerulenin (b) and orlistat (c), when compared with their respective controls (DMSO or ETOH). Cell cycle analysis by flow cytometry show that the incubation of HDLEC cells with $2.5 \mu \mathrm{g} / \mathrm{ml}$ of cerulenin (d) or $100 \mu \mathrm{M}$ of orlistat (e) for $24 \mathrm{~h}$ enhanced the G0-G1 population and reduced the percentage of cells in

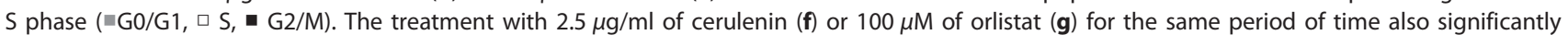
increased the percentage of apoptotic HDLEC cells. ${ }^{*} P<0.05$, Student's $t$-test. Error bars indicates mean $\pm s$.d. of at least three independent experiments.

$10 \mathrm{~min}$, and $40 \mathrm{cycles}$ of $95^{\circ} \mathrm{C}$ for $15 \mathrm{~s}$ and $57^{\circ} \mathrm{C}$ for $1 \mathrm{~min}$ in a StepOne Plus Real-Time PCR System (Applied Biosystems). Primer sequences are listed in Supplementary Table 2 and the relative gene expression determined by the $2^{-\Delta \Delta} \mathrm{CT}$ or standard curve methods with the aid of the SDS software version 2.0 .

\section{Conditioned Media and ELISA}

Conditioned media were obtained by seeding $3 \times 10^{5}$ B16-F10 cells in $100 \mathrm{~mm}$ culture dishes with complete growth medium. After $24 \mathrm{~h}$, medium was changed by fresh medium containing 50,100 , or $300 \mu \mathrm{M}$ of orlistat supplemented with $1 \%$ FBS, which was collected after additional $24 \mathrm{~h}$. Cells and 

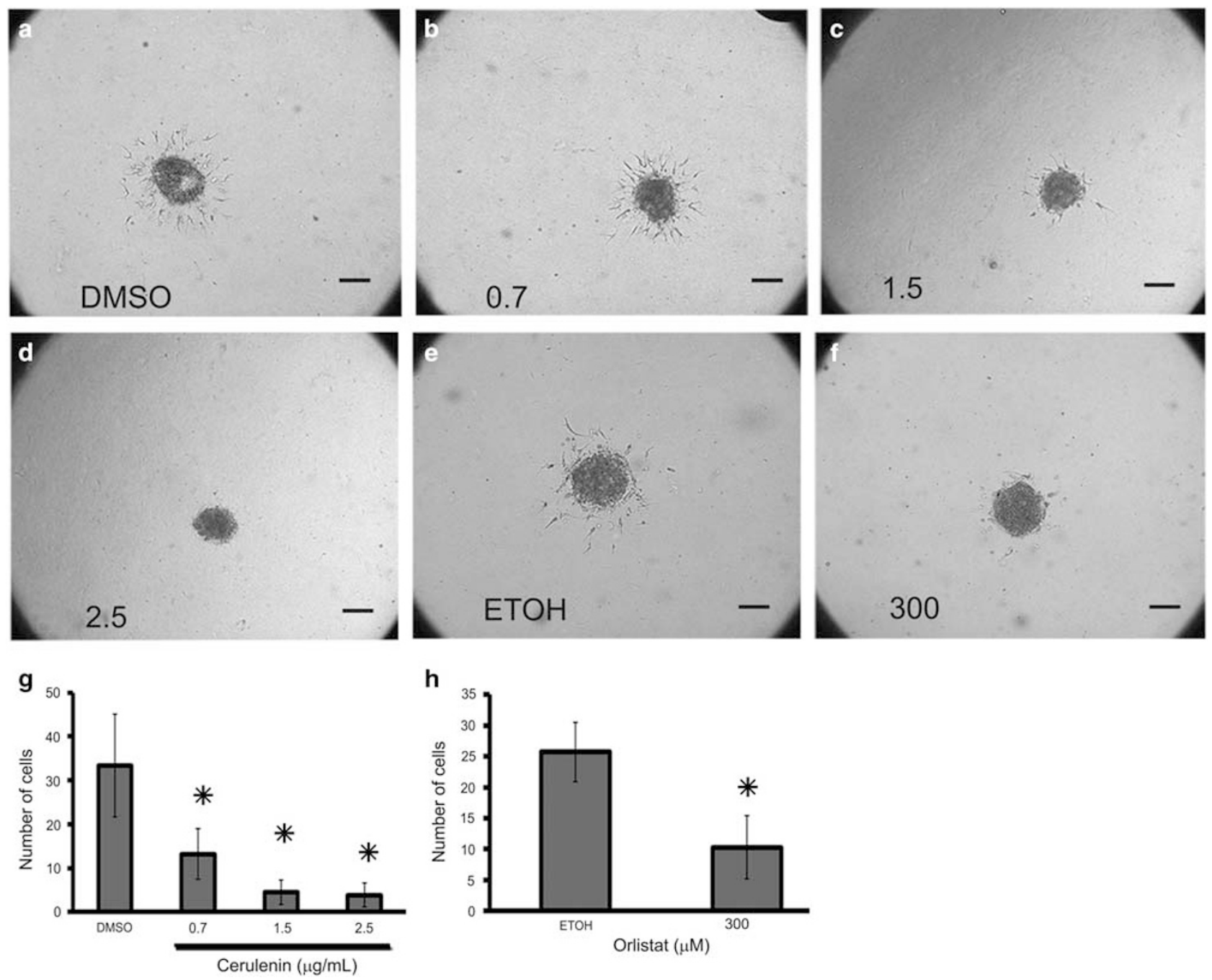

Figure 2 Fatty acid synthase inhibitors decrease migration of lymphatic endothelial cells. Representative phase-contrast microscopy aspects of hTertHDLEC spheroids in the presence of DMSO (a), $0.7,1.5$, and $2.5 \mu \mathrm{g} / \mathrm{ml}$ of cerulenin (b-d) or ETOH (e) and $300 \mu \mathrm{M}$ of orlistat (f). The number of cells spreading from the spheroids after $24 \mathrm{~h}$ was significantly higher in the controls than following the treatment with cerulenin $(\mathbf{g})$ or orlistat $(\mathbf{h}){ }^{*} P<0.05$, Student's $t$-test. Scale bars, $500 \mu \mathrm{m}$ (a-f). Error bars indicates mean \pm s.d. of at least three independent experiments.

debris were removed by centrifugation at $1100 \mathrm{~g}$ for $3 \mathrm{~min}$, and conditioned medium $(30 \%$ conditioned medium from B16-F10 cells and 70\% fresh medium supplemented with $1 \%$ of FBS) used to treat the spheroids (8-10 spheroids per well, 2 wells for each condition). The concentration of VEGF-D in the conditioned media was determined by the VEGF-D enzyme-linked immunosorbent assay (Mouse VEGF-D DuoSet ELISA, R\&D Systems, Minneapolis, MN, USA) following the manufacturer's instructions. SK-Mel-25 cells $\left(4 \times 10^{5}\right)$ were seeded in T-25 flasks with growth medium without antibiotics containing $10 \%$ of FBS. After $24 \mathrm{~h}$, cells were serum starved for additional $24 \mathrm{~h}$ and the medium changed by fresh medium containing cerulenin or orlistat, which was collected after $48 \mathrm{~h}$. Cells and debris were removed by centrifugation at $1100 \mathrm{~g}$ for $3 \mathrm{~min}$ the concentration of VEGF$\mathrm{C}$ and $-\mathrm{D}$ in the conditioned media determined by ELISA
(Human VEGF-C Quantikine ELISA and Human VEGF-D DuoSet ELISA, R\&D Systems).

\section{siRNA-Silencing of FASN Expression}

The 25-mer RNA molecules were synthesized, annealed, and purified by the manufacturer (Stealth RNAi, Invitrogen). The following sequences targeting Mus musculus FASN (NM_00798) were used: 5'-CAA TGA TGG CCA ACC GGC TCT CTT T $3^{\prime}$ ), $5^{\prime}$-TGG GAA GAC CCG AAC TCC AAG TTA T-3', and 5'-CCT CTG GGC ATG GCT ATC TTC TTG A-3'. B16-F10 cells grown to 50\% confluence were transfected with $200 \mathrm{nM}$ of a mixture containing equal parts of specific siRNAs using a liposome method according to manufacturer's instructions (Lipofectamine 2000, $3 \mu \mathrm{l} / \mathrm{ml}$, Invitrogen). As negative controls, cells were transfected with equimolar concentrations of a nonspecific control oligo 
(Stealth RNAi Negative Control Duplexes, Medium GC Duplex, Invitrogen). FASN knockdown was assessed by western blotting after $48 \mathrm{~h}$.

\section{RESULTS}

\section{FASN Inhibitors Reduce Proliferation and Promote Apoptosis in HDLEC Cells}

As depicted in Figure 1a, similar to the cancer-derived cell lines SCC-9, SK-Mel-25, and B16-F10, cultured HDLEC cells are high FASN protein producers. The viability of HDLEC cells was slightly reduced in the presence of all tested concentrations of cerulenin (Figure 1b) and orlistat (Figure 1c), in comparison with the respective controls. Cell cycle analysis by flow cytometry show that the incubation of HDLEC cells with $2.5 \mu \mathrm{g} / \mathrm{ml}$ of cerulenin (Figure 1d) or $100 \mu \mathrm{M}$ of orlistat (Figure 1e) for $24 \mathrm{~h}$ enhances the G0-G1 population and reduces the percentage of cells in S phase. The same concentrations of these drugs also significantly increased the percentage of apoptotic HDLEC cells (Figures $1 \mathrm{f}$ and g). These results show that primary cultures of lymphatic endothelial cells actively synthesize FASN and are sensitive to FASN inhibitors.

\section{FASN Inhibitors Decrease Migration of Lymphatic Endothelial Cells and Lymphatic Outgrowth}

To better understand the effects of FASN inhibitors on the lymphatic vasculature, we next tested the impact of cerulenin or orlistat on hTERT-HDLEC cells in the spheroid migration assay. These studies show that all tested concentrations of these drugs (Figures $2 \mathrm{a}-\mathrm{f}$ ) reduced lymphatic endothelial cell migration, which was assessed by counting the number of cells isolated from the spheroids after $24 \mathrm{~h}$ (Figures $2 \mathrm{~g}$ and $\mathrm{h}$ ). The treatment with 2 or $2.5 \mu \mathrm{g} / \mathrm{ml}$ of cerulenin and 100 or $300 \mu \mathrm{M}$ of orlistat also reduced lymphatic endothelial cell outgrowth from cultured explants of mice lymphatic ducts when compared with their respective vehicles (Figures $3 \mathrm{a}-\mathrm{f}$ ). The outgrowth of lymphatic cells in the DMSO controls reached the maximal distance of $1.15 \mathrm{~mm}$, which was reduced by $35 \%$ in the cerulenin-treated explants (Figures $3 \mathrm{~g}$ and $\mathrm{h}$ ). Similarly, the maximum distance reached by lymphatic cells in $\mathrm{ETOH}$ was $1 \mathrm{~mm}$ and did not exceed $0.7 \mathrm{~mm}$ (30\% of reduction) in the presence of orlistat (Figure 3i).

\section{FASN Inhibitors Differentially Modulate VEGF-C and -D in Melanoma Cells}

To verify a role for FASN inhibitors on the melanomainduced lymphangiogenesis, we next analyzed the production of VEGF-C and -D in cultured B16-F10 and SK-Mel-25 cells treated with cerulenin or orlistat. Enhanced secretion of VEGF-D by cerulenin- and orlistat-treated B16-F10 cells was verified by ELISA, which was further confirmed by the FASN knockdown with specific siRNAs (Figures $4 a-d$ ). Both drugs stimulated the secretion of VEGF-D and reduced the production of VEGF-C in SK-Mel-25 cells (Figures 4e-h). In addition, the immunopositivity for VEGFR-3 was significantly reduced in HDLEC cells treated with cerulenin or orlistat (Figures $4 i$ and $j$ ).

\section{Orlistat Reduces the Size of Lymph Node Metastases and its VEGF-C Expression}

Once intradermally injected in the $\mathrm{C} 57 \mathrm{Bl} / 6$ mice ears, B16F10 cells develop primary tumors and lymph node metastases in approximately one week and 20 days, respectively (Figures $5 \mathrm{a}$ and $\mathrm{b}$ ). The most frequent pattern of metastatic spread was bilaterally to the lateral superficial cervical lymph nodes (Figure 5b), although unilateral lymph node metastasis were also found. Importantly, the lateral superficial cervical lymph node metastases from the orlistat-treated mice were $39.25 \%$ smaller than the metastases found in the control animals $(P<0.05$, Student's $t$-test) (Figure $5 \mathrm{c})$. The volumes of primary tumors were calculated and no differences between the control and orlistat-treated groups were detected (data not shown). Histologically, the primary tumors from the two experimental groups were indistinguishable and characterized by malignant melanocytes with hyperchromatic nuclei, multiple nucleoli, cytoplasmic melanin accumulation, and atypical mitoses, generally adjacent to the ear cartilage (Figure 5d). The lymph node metastases were microscopically confirmed and characterized by the peripheral infiltration of B16-F10 cells (Figure 5e). As depicted in Figures $5 f$ and g, the effectiveness of systemic FASN inhibition with orlistat was demonstrated by the observation of Oil red $\mathrm{O}$ stained liver frozen sections, in which the hepatocytes from control mice were rich in large lipid droplets, in contrast with the weakly stained cells from the orlistat-treated group. Interestingly, the intensity of FASN protein bands were increased in lysates from primary tumors of orlistat-treated mice, in comparison with the control mice, possibly as a feedback response (Supplementary Figures S1a and b). As depicted in Figures $5 \mathrm{~h}$ and i, orlistat did not affect the expression of VEGF-D, but decreased VEGF-C levels in experimental lymph node metastasis. Interestingly, the transcripts for both growth factors in the primary tumors were not affected by this drug (data not shown). Despite the well characterized anti-obesity properties of orlistat, the body weight of treated mice was not affected.

\section{Orlistat Enhances Lymphatic Staining by FITC-Dextran In vivo}

To check whether the treatment with orlistat affects the lymphatic vasculature, we first examined the lymphatic network at the periphery of surgical wounds performed in Balb-C mice ears. Twenty five days after the beginning of the treatment with orlistat, fluorescent dextran microlymphangiographies revealed more positive lymphatic vessels in treated than in control mice (Figures $6 \mathrm{a}$ and b). Similar observations were made in B16-F10 peritumoral lymphatics, which after the treatment with orlistat were denser than the controls (Figures 6d and e). Although in a lesser extent, the lymphatic vessel density was also higher in the ears of orlistattreated mice without surgical wounds or experimental 

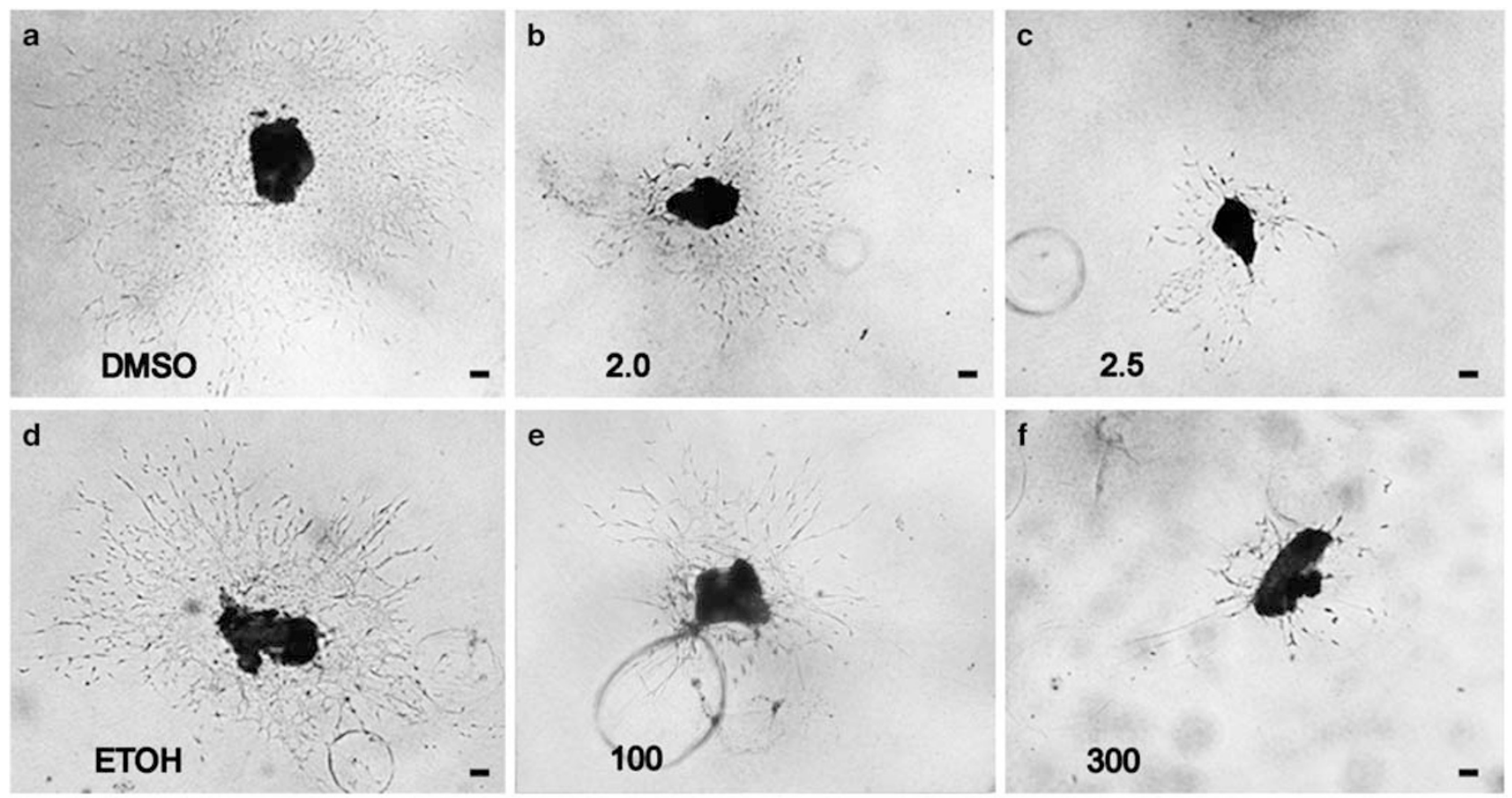

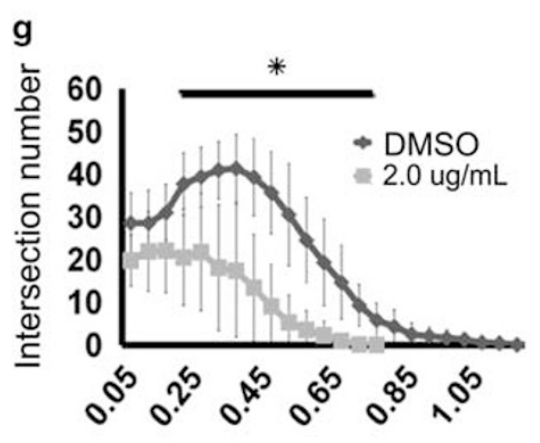

$\mathrm{mm}$ from the explant

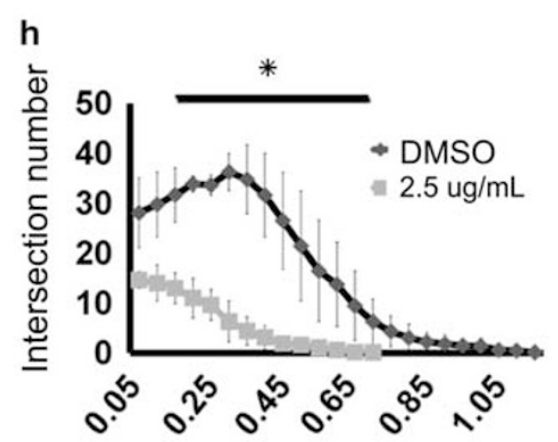

$\mathrm{mm}$ from the explant

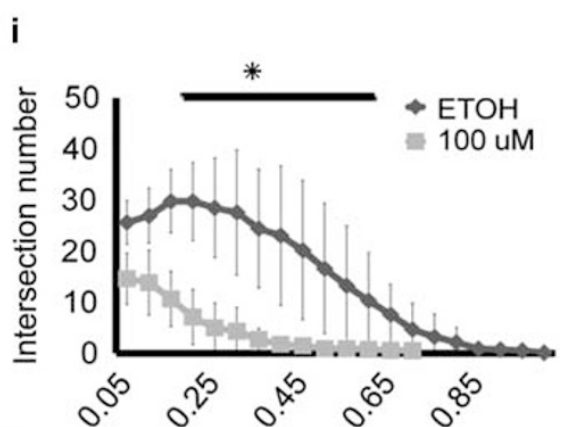

$\mathrm{mm}$ from the explant

Figure 3 Cerulenin and orlistat inhibit the lymphatic capillary growth in the lymphatic ring assay. The treatment with 2 (b) or $2.5 \mu \mathrm{g} / \mathrm{ml}$ (c) of cerulenin promoted an anti-lymphangiogenic effect on the explants from mice lymphatic ducts when compared with the DMSO controls (a). Orlistat also reduced capillary formation at 100 (e) in comparison with the ETOH controls (d). The capillary growth was strongly affected by $300 \mu \mathrm{M}$ of orlistat (f). The growth of lymphatic structures in the DMSO controls ( $\square$ ) reached the maximal distance of $1.15 \mathrm{~mm}$, whereas the treatment with 2 or $2.5 \mu \mathrm{g} / \mathrm{ml}$ of cerulenin ( $\square$ ) reduced this distance to $0.75 \mathrm{~mm}$ (35\%) ( $\mathbf{g}$ and $\mathbf{h})$. The higher distance reached by lymphatic structures in ETOH ( $\square$ ) was $1 \mathrm{~mm}$, which did not exceed $0.7 \mathrm{~mm}$ (i) in presence of $100 \mu \mathrm{M}$ of orlistat ( $匚$ ). Two independent experiments were evaluated (explants per condition: DMSO $n=15 ; 2$ and $2.5 \mu \mathrm{g} / \mathrm{ml} n=12$; ETOH $n=14 ; 100 \mu \mathrm{M} n=10)$. ${ }^{*} P<0.05$, Student's $t$-test. Scale bars, $500 \mu \mathrm{m}(\mathbf{a}-\mathbf{f})$. Error bars indicates mean $\pm \mathrm{s}$.d. of at least three independent experiments.

melanomas, suggesting that the drug systemically changes lymphatic vessel architecture and/or permeability (Figures $6 \mathrm{~g}$ and $\mathrm{h}$ ). The quantitative analysis of lymphatic vessel densities confirmed the higher lymphatic density in the orlistat-treated mice from the three experimental models (Figures $6 \mathrm{c}, \mathrm{f}$ and i). These animals showed no significant physical or behavioral alterations during the period of treatment.

\section{Conditioned Medium from B16-F10 Cells Treated with Cerulenin or Orlistat Reduce the Filopodia-Like Cell Extensions of Cultured Lymphatic Endothelial Cells}

To better understand the effects of FASN inhibitors on the lymphatic vasculature, we next used conditioned medium from mouse melanoma cells to incubate hTERT-HDLEC cells in the spheroid assay. Conditioned medium from cerulenin(Figures $7 \mathrm{~b}$ and e) or orlistat-treated (Figures 7d and f) B16F10 cells did not affect lymphatic endothelial cell migration in comparison with the respective controls (Figures $7 \mathrm{a}$ and c). However, the number of cells without filopodia-like extensions was significantly higher in the presence of cerulenin or orlistat and the number of cells with three or more of these structures was higher in the controls (Figures $7 \mathrm{~g}$ and $\mathrm{h}$ ).

\section{DISCUSSION}

The association between FASN expression and activity with tumor growth, metastasis, and prognosis has been 


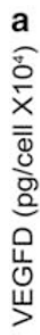
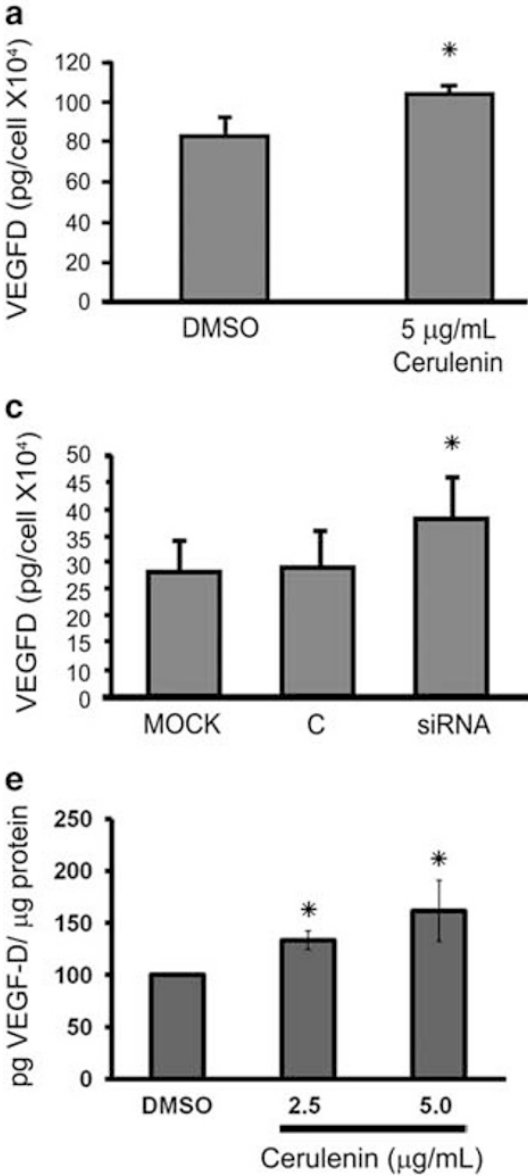

g

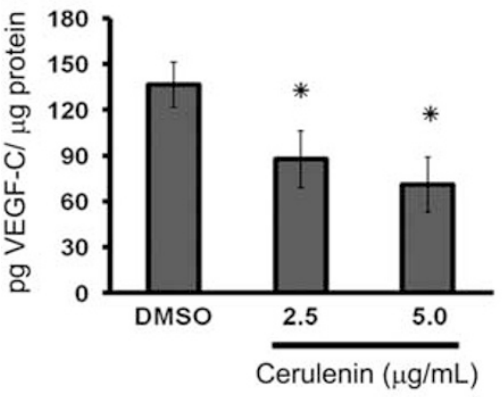

i

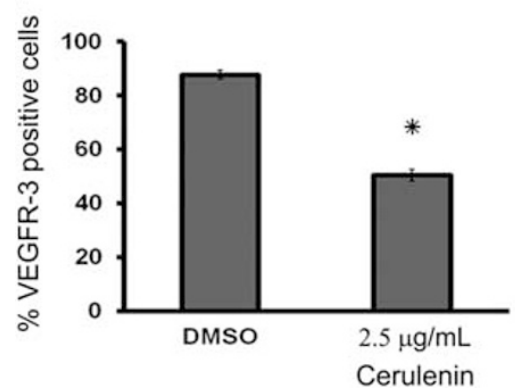

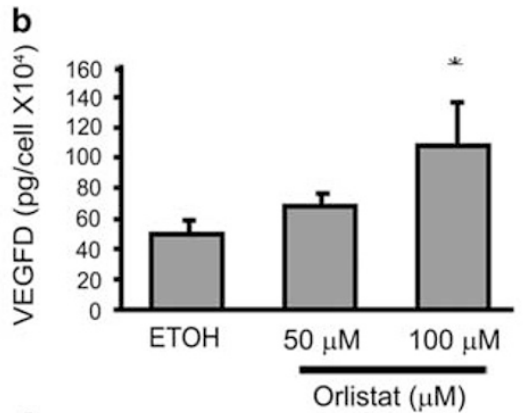

d

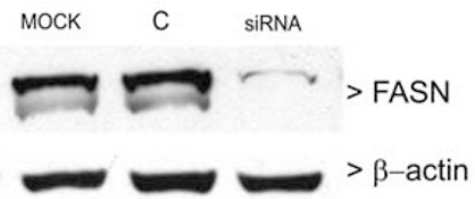

f

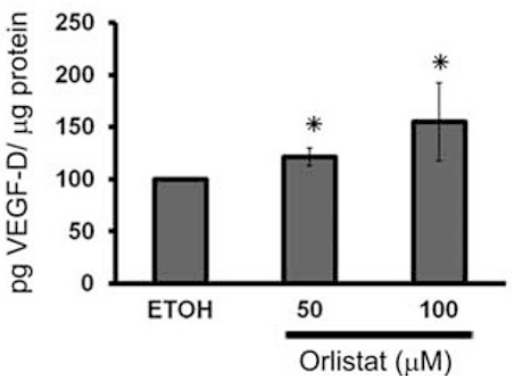

h

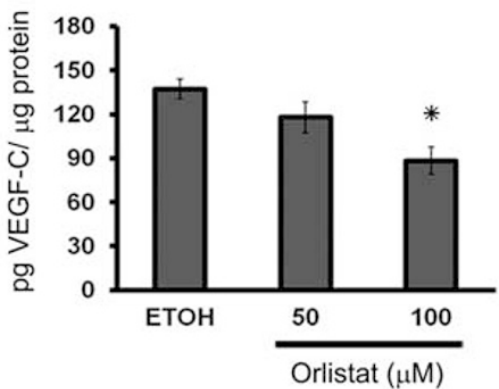

j

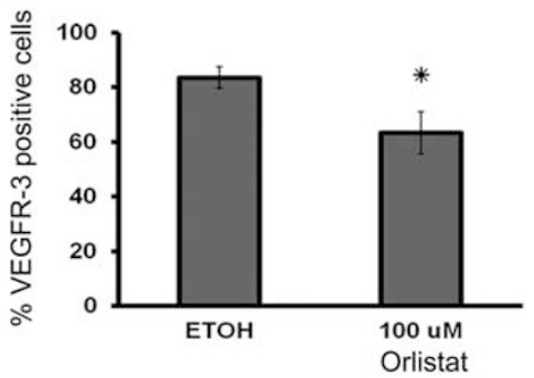

Figure 4 Effects of fatty acid synthase (FASN) inhibitors on vascular endothelial growth factor C and D (VEGF-C and -D) production by melanoma cells. VEGF-D concentration was significantly increased in the conditioned medium from both cerulenin and orlistat-treated B16-F10 cells as well as after the transfection with siRNAs specific for FASN (a-c). (d) Representative western blotting confirming FASN knockdown in the siRNA-transfected B16-F10 cell lysates. VEGF-D concentration was also significantly increased in the conditioned medium from cerulenin or orlistat-treated SK-Mel-25 cells (e, f). In contrast, the production of VEGF-C by SK-Mel-25 cells was reduced in the same experimental conditions $(\mathbf{g}, \mathbf{h})$. The number of VEGFR-3 positive HDLEC cells was also reduced by cerulenin (i) and orlistat (j). ${ }^{*} P<0.05$, Student's $t$-test. Error bars indicates mean \pm s.d. of at least three independent experiments. 
demonstrated in several types of human malignancies. ${ }^{3}$ In fact, fatty acid biosynthesis within tumor tissues occurs at high rates regardless nutritional supply, ${ }^{46,47}$ and FASN blockage or knockdown inhibits proliferation and promotes apoptosis in cultured cancer cell lines. ${ }^{13,15-17,48-50}$

It is generally accepted that normal human tissues preferentially use dietary fat for the synthesis of new structural lipids and the de novo fatty acid synthesis is maintained at low levels. ${ }^{11,51}$ Herein, we show that FASN is critical for both proliferation and survival of HDLEC cells, as cerulenin and orlistat significantly reduced their growth, viability, and induced apoptosis. However, the mechanisms by which FASN inhibition affects these processes in malignant and nonmalignant cells remain to be elucidated. We also show in the present study that these drugs inhibit HDLEC lateral migration in the spheroid assay and decrease the growth of murine lymphatic capillaries in the ex vivo model providing the first evidence of their anti-lymphangiogenic activity. These findings are in agreement with those from Browne et al, ${ }^{18}$ which showed that pharmacological inhibition of FASN with orlistat decreases ex vivo human neovascularization. Recent studies from our group demonstrate that orlistat reduces the viability and proliferation of rabbit aortic endothelial cells as well as impairs the development of capillary-like structures by the same cells in Matrigel. ${ }^{51}$ Therefore, the results here presented corroborate the growing body of evidence indicating that FASN is also needed for the growth and maintenance of nonmalignant cells. ${ }^{18,51,52}$

VEGF family members orchestrate both angiogenic and lymphangiogenic processes in physiological and pathological conditions. VEGF-A, -B, -E, -F, and PIGF act in angiogenesis and vasculogenesis, whereas full-length VEGF-C and -D preferentially bind to VEGFR-3 to promote lymphangiogenesis. ${ }^{25,26}$ Although elevated levels of both VEGF-C and -D are associated with increased lymphangiogenesis and metastasis in mouse tumor models, ${ }^{30-34}$ studies with clinical samples have suggested a role for VEGF-C, but not VEGF-D, in metastatic spread and prognosis. ${ }^{27}$ In fact, elevated VEGF-C levels seems to correlate with lymph node metastasis in a variety of human cancers such as breast, colon, rectum, prostate, esophagus, stomach, lung, uterine cervix, endometrium, and melanomas, ${ }^{53,54}$ in which VEGF-C production is high in the vertical phase of growth. $^{35,55}$ Conversely, the role of VEGF-D in lymph node metastasis in melanomas remains unclear. ${ }^{35}$ Our results show increased
VEGF-D and reduced VEGF-C in B16-F10 and SK-Mel-25 cells treated with both cerulenin and orlistat. In addition, HDLEC cell proliferation was significantly inhibited by conditioned media from cerulenin- or orlistat-treated SKMel-25 cells (data not shown), further suggesting that FASN inhibitors produce an anti-lymphangiogenic phenotype in melanoma cells. Interestingly, the treatment with orlistat did not affect VEGF-D expression in our primary melanomas and their metastases; however, decreased VEGF-C mRNAs were found in the latter. We speculate that VEGF-D changes in primary tumors were not detected because of their complex microenviroment, which may mask the drug effects.

Previous results from our group show that orlistat reduces experimental melanoma ${ }^{16}$ and oral squamous cell carcinoma metastasis, ${ }^{56}$ and that FASN may have a role in tumor angiogenesis. ${ }^{51}$ In fact, Seguin et al ${ }^{51}$ showed reduced formation of HUVEC capillary-like structures in culture medium previously conditioned by orlistat-treated SK-Mel-25 cells because of the enhanced production of the inhibitory isoform VEGF- $A_{165 b}$ by melanoma cells. In agreement with these results, Zaytseva et al ${ }^{57}$ demonstrated that the knockdown of FASN resulted in downregulation of $\mathrm{VEGF}_{189}$ and upregulation $\mathrm{VEGF}_{165 \mathrm{~b}}$ in colorectal cancer cell lines. In addition, Menendez et al ${ }^{58}$ demonstrated that FASN inhibition with C75 increases the production of total VEGF-A and accumulates HIF- $1 \alpha$ in breast cancer cells, suggesting a hypoxia-like response. Accordingly, here we show that the size of lymph node metastases from experimental cutaneous melanomas is significantly reduced by the treatment with orlistat. As in our previous study with B16-F10 tumors, ${ }^{16}$ orlistat did not affect primary tumor size, which can be explained by their rapid growth and aggressiveness at the time of their metastatic spread. Despite the relevant results obtained in vitro, the use of cerulenin in vivo is limited because of its chemical instability. ${ }^{58}$

The association between FASN inhibitiors and production of lymphangiogenic growth factors by cancer cells has not yet been described. However, hypoxia enhances VEGF-D and VEGFR-3 mRNAs in vein endothelial cells and regulates VEGF-D activity in smooth muscle cells..$^{59,60}$ Hypoxia is also associated with lymphangiogenesis, lymphatic differentiation, and VEGF-A, VEGF-C, and VEGF-D expression in cervical cancer cells. ${ }^{61}$ Moreover, VEGF-D expression is associated with HIF- $1 \alpha$ in breast cancer tissues. ${ }^{62}$ Recently, Sounni et $a^{63}$ showed that the inhibition of the de novo lipogenesis with orlistat in human and mouse breast, colon and lung

Figure 5 Effects of orlistat on the experimental B16-F10 melanomas. (a) Representative tumors (arrows) grown after bilateral intradermal inoculation of B16-F10 cells in the ears of C57BI/6 mice. (b) Bilateral lateral superficial cervical lymph node metastases (arrows) in the same animal shown in a. (c) The treatment with orlistat significantly reduced the size of lymph node metastases. Hematoxylin and eosin-stained sections from one of the primary tumors shown in a demonstrate highly pleomorphic cells and intense melanin accumulation adjacent to the ear cartilage (d). Melanoma cells (arrows) were observed at the periphery of affected lymph nodes (e). Representative Oil red O staining of a control liver frozen section showing many large lipid droplets (red) (f), in contrast with a sample from an orlistat-treated mice (g). qRT-PCR analysis of vascular endothelial growth factor C (h) and vascular endothelial growth factor $D(\mathbf{i})$ in the metastatic lymph nodes shows that the former is significantly decreased by the treatment with orlistat. (d-g) original magnification $\times 400$; ${ }^{*} P<0.05$, Student's $t$-test. Error bars indicates mean \pm s.d. of at least three independent experiments. 

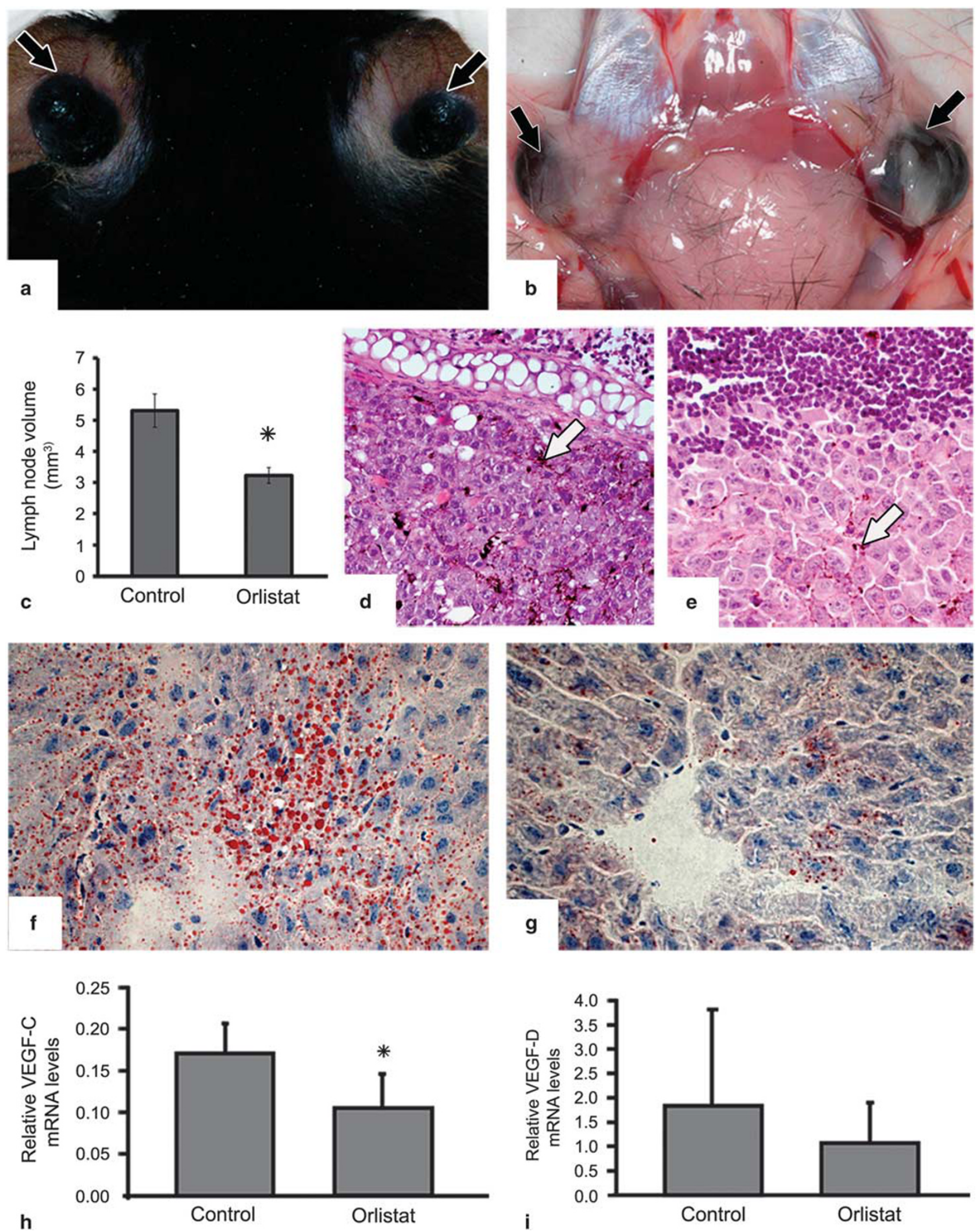

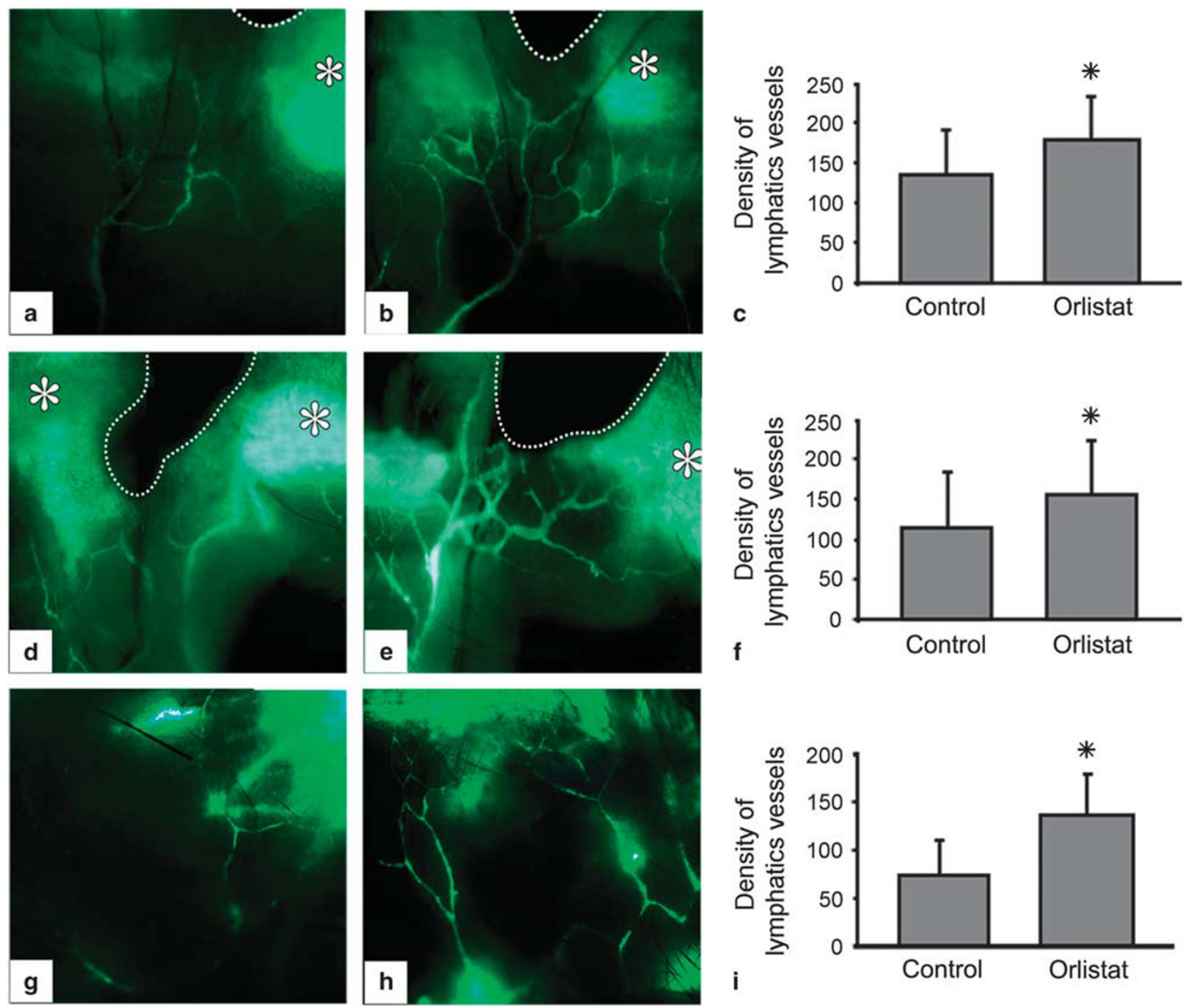

Figure 6 Orlistat increases lymphatic vessel density and permeability. Following the systemic treatment with orlistat, fluorescent dextran microlymphangiography was performed in three distinct experimental models: 25 days after the preparation of a $1.5 \mathrm{~mm}$ surgical wound in the central portion of the ears of Balb-C mice (a, b), 20 days following the inoculation of B16-F10 melanoma cells in the ears of C57BI/6 mice (d, e), and in the ears of C57BI/6 mice without surgical wounds or experimental tumors $(\mathbf{g}, \mathbf{h})$. The lymphatic vessel networks were denser in orlistat-treated mice $(\mathbf{b}$, e, $\mathbf{h})$ than in control animals $(\mathbf{a}, \mathbf{d}, \mathbf{g})$. Lymphatic vessel densities were calculated with the aid of an image software in predeterminated circular areas (c, $\mathbf{f}$, i). Asterisks show the site of FITC-dextran injections; doted lines delimit the area of the surgical wounds or experimental tumors. ${ }^{*} P<0.05$, Student's $t$-test. Error bars indicates mean \pm s.d. of at least three independent experiments.

models reduces tumor regrowth after the treatment with antiangiogenic therapy with sunitinib or sorafenib suggesting a link between therapeutic resistance to these drugs and lipid metabolism. Nevertheless, the lymphatic endothelial growth inhibition and induction of apoptosis observed in our in vitro studies did not reflect the results from the animal models, where orlistat-treated mice showed increased lymphatic permeability. We speculate that the decreased lymphatic endothelial cell extensions observed after incubation with conditioned medium from orlistat- or cerulenin-treated melanoma cells enhances lymphatic vessel permeability. In addition, filopodial outgrowth depends on actin polymerization at the glycerophospholipid PtdIns $(4,5) \mathrm{P}_{2}$ and $(3,4,5) \mathrm{P}_{3}$, composed by fatty acids with 16-20 carbon molecules, that are critical for the membrane-cytoskeleton interactions via activation of the PI3K pathway. ${ }^{64,65}$ In fact, FASN pharmacological inhibition reduces the synthesis of phospholipids incorporated into lipids rafts, detergent-resistant microdomains, which act as platforms for signal transduction, including via PI3K. ${ }^{66}$ Despite the fact that the involvement of FASN in filopodia outgrowth is largely unknown, our results suggest that FASN inhibitors may change lymphatic endothelial cell-to-cell or cell-to-matrix contacts and perhaps increase lymphatic permeability.

In summary, the present study shows that orlistat reduces the size of lymph node metastasis from experimental 

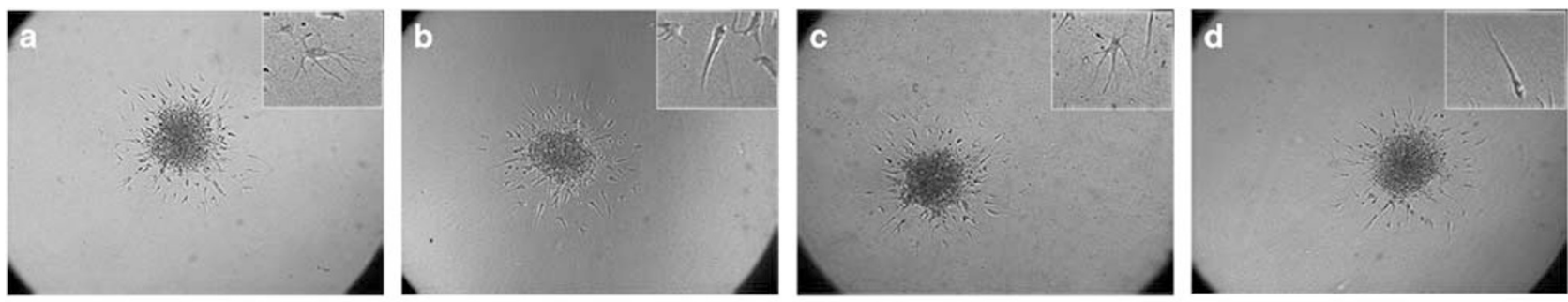

e

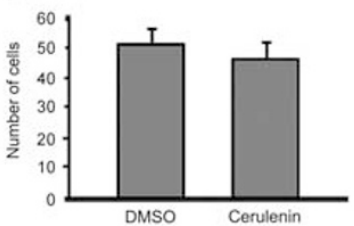

f

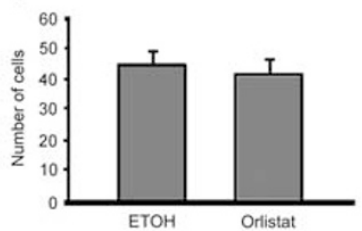

g

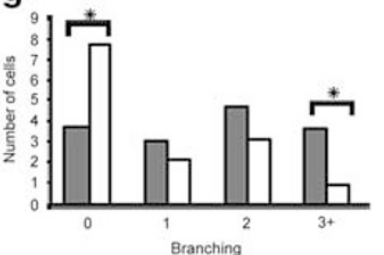

h

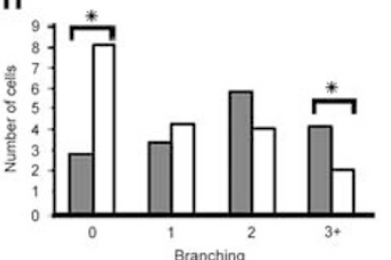

Figure 7 Conditioned medium from B16-F10 melanoma cells reduces the growth of filopodia-like cell extensions. Conditioned medium from B16-F10 melanoma cells treated with cerulenin or orlistat does not inhibit the lateral endothelial cell migration (a-f), however, reduces the growth of filopodialike cell extensions in the spheroid migration assay with hTert-HDLEC cells $(\mathbf{g}, \mathbf{h})$. Representative phase-contrast photomicrographies of the spheroids in the presence of control media (a, c) or conditioned media from B16-F10 cells treated with cerulenin (b) or orlistat (d). The number of cells without filopodia-like cell extensions (detail in $\mathbf{b}$ and $\mathbf{d}$ ) is significantly enhanced in the presence of conditioned media from B16-F10 cells treated with both FASN inhibitors (white bars), whereas the number of cells with three or more cell extensions (detail in a and $\mathbf{c}$ ) is higher in the presence of the control media $(\mathbf{g}, \mathbf{h})$. Gray bars: control media; ${ }^{*} P<0.05$, Student's $t$-test. Error bars indicates mean \pm s.d. of at least three independent experiments.

melanomas and enhances lymphatic vessel permeability. In addition, conditioned culture media from orlistat- or cerulenin-treated B16-F10 cells decrease the number of filopodia-like cell extensions of endothelial lymphatic cells. Both FASN inhibitors decrease lymphatic endothelial cell proliferation, migration, and VEGFR-3 expression, as well as promote apoptosis. Finally, these compounds increase VEGF$\mathrm{D}$ and inhibit VEGF-C production by human melanoma cells. Altogether, our results suggest that FASN inhibitors act both on lymphatic endothelial cells and melanoma cells to promote an anti-lymphangiogenic phenotype.

Supplementary Information accompanies the paper on the Laboratory Investigation website (http://www.laboratoryinvestigation.org)

\section{ACKNOWLEDGMENTS}

This work was supported by the Fundação de Amparo à Pesquisa do Estado de São Paulo (FAPESP), Grants 2008/57471-7 and 2014/20832-3. DCB, FS, MA, MAC were supported by FAPESP fellowships (2010/51090-1, 2010/50946-0, 2008/55548-2, 2007/58158-8). AN, JP and CM were supported by grants from the Fonds de la Recherche Scientifique (FNRS) and the Foundation against Cancer (Belgium)

\section{DISCLOSURE/CONFLICT OF INTEREST}

The authors declare no conflict of interest.

1. Wakil SJ. Fatty acid synthase, a proficient multifunctional enzyme. Biochemistry 1989;11:4523-4530.

2. Kusakabe $\mathrm{T}$, Maeda $\mathrm{M}$, Hoshi N, et al. Fatty acid synthase is expressed mainly in adult hormone-sensitive cells or cells with high lipid metabolism and in proliferating fetal cells. J Histochem Cytochem 2000;5:613-622.

3. Flavin R, Peluso S, Nguyen PL, et al. Fatty acid synthase as a potential therapeutic target in cancer. Future Oncol 2010;4:551-562.
4. Innocenzi D, Alo PL, Balzani A, et al. Fatty acid synthase expression in melanoma. J Cutan Pathol 2003;30:23-28.

5. Rossi S, Graner E, Febbo P, et al. Fatty acid synthase expression defines distinct molecular signatures in prostate cancer. Mol Cancer Res 2003:10:707-715.

6. Takahiro T, Shinichi K, Toshimitsu S. Expression of fatty acid synthase as a prognostic indicator in soft tissue sarcomas. Clin Cancer Res 2003;6:2204-2212.

7. Visca P, Sebastiani V, Botti C, et al. Fatty acid synthase (FAS) is a marker of increased risk of recurrence in lung carcinoma. Anticancer Res 2004;6:4169-4173.

8. Ogino S, Nosho K, Meyerhardt JA, et al. Cohort study of fatty acid synthase expression and patient survival in colon cancer. J Clin Oncol 2008:35:5713-5720.

9. Silva SD, Cunha IW, Nishimoto IN, et al. Clinicopathological significance of ubiquitin-specific protease 2a (USP2a), fatty acid synthase (FASN), and ErbB2 expression in oral squamous cell carcinomas. Oral Oncol 2009:10:134-139.

10. Kuhajda FP, Katumuluwa Al, Pasternack GR. Expression of haptoglobinrelated protein and its potential as a tumor antigen. Proc Natl Acad Sci USA 1989;86:1188-1192.

11. Kuhajda FP, Jenner K, Wood FD, et al. Fatty acid synthesis: a potential selective target for antineoplastic therapy. Proc Natl Acad Sci USA 1994;91:6379-6383.

12. Vazquez-Martin A, Colomer R, Brunet J, et al. Overexpression of fatty acid synthase gene activates HER1/HER2 tyrosine kinase receptors in human breast epithelial cells. Cell Prolif 2008;1:59-85.

13. Migita $T$, Ruiz $S$, Fornari $A$, et al. Fatty acid synthase: a metabolic enzyme and candidate oncogene in prostate cancer. J Natl Cancer Inst 2009;7:519-532.

14. Menendez JA, Lupu R. Fatty acid synthase and the lipogenic phenotype in cancer pathogenesis. Nat Rev Cancer 2007;10:763-777.

15. Kridel SJ, Axelrod F, Rosenkrants N, et al. Orlistat is a novel inhibitor of fatty acid synthase with antitumor activity. Cancer Res 2004;64:2070-2075.

16. Carvalho MA, Zecchin KG, Seguin F, et al. Fatty acid synthase inhibition with Orlistat promotes apoptosis and reduces cell growth and lymph node metastasis in a mouse melanoma model. Int J Cancer 2008;11: 2557-2565.

17. Zecchin KG, Rossato FA, Raposo HF, et al. Inhibition of fatty acid synthase in melanoma cells activates the intrinsic pathway of apoptosis. Lab Invest 2011;2:232-240. 
18. Browne CD, Hindmarsh EJ, Smith JW. Inhibition of endothelial cell proliferation and angiogenesis by orlistat, a fatty acid synthase inhibitor. FASEB 2006;20:2027-2035.

19. Swartz MA, Skobe M. Lymphatic function, lymphangiogenesis, and cancer metastasis. Microsc Ras Tech 2001;2:92-99.

20. Paupert J, Sounni NE, Noël A. Lymphangiogenesis in post-natal tissue remodeling: lymphatic endothelial cell connection with its environment. Mol Aspects Med 2011;2:146-158.

21. Tammela T, Alitalo K. Lymphangiogenesis: molecular mechanisms and future promise. Cell 2010;4:460-476.

22. Al-Rawi MA, Mansel RE, Jiang WG. Lymphangiogenesis and its role in cancer. Histol Histopathol 2005;1:283-298.

23. Alitalo K. The lymphatic vasculature in disease. Nat Med 2011;11: 1371-1380.

24. Lohela M, Bry M, Tammela T, et al. VEGFs and receptors involved in angiogenesis versus lymphangiogenesis. Curr Opin Cell Biol 2009;2: 154-165.

25. Joukov V, Pajusola K, Kaipainen A, et al. A novel vascular endothelial growth factor, VEGF-C, is a ligand for the Flt-4 (VEGFR-3) and KDR (VEGFR-2) receptor kinases. EMBO J 1996;2:290-298.

26. Achen $M G$, Jeltsch $M$, Kukk $E$, et al. Vascular endothelial growth factor D (VEGF-D) is a ligand for the tyrosine kinases VEGF receptor (FIk-1) and VEGF receptor 3 (Flt-4). Proc Natl Acad Sci USA 1998;95:548-553.

27. Alitalo A, Detmar M. Interaction of tumor cells and lymphatic vessels in cancer progression. Oncogene 2012;31:4499-4508.

28. Harris NC, Paavonen K, Davydova N, et al. Proteolytic processing of vascular endothelial growth factor-D is essential for its capacity to promote the growth and spread of cancer. FASEB J 2011;25: 2615-2625.

29. Anisimov A, Alitalo A, Korpisalo $\mathrm{P}$, et al. Activated forms of VEGF-C and VEGF-D provide improved vascular function in skeletal muscle. Circ Res 2009;104:1302-1312.

30. He Y, Rajantie I, Pajusola K, et al. Vascular endothelial cell growth factor receptor 3-mediated activation of lymphatic endothelium is crucial for tumor cell entry and spread via lymphatic vessels. Cancer Res 2005;65: 4739-4746.

31. Burton JB, Priceman SJ, Sung JL, et al. Suppression of prostate cancer nodal and systemic metastasis by blockade of the lymphangiogenic axis. Cancer Res 2008;68:7828-7837.

32. Skobe M, Hawighorst $\mathrm{T}$, Jackson DG, et al. Induction of tumor lymphangiogenesis by VEGF-C promotes breast cancer metastasis. Nat Med 2001;7:192-198.

33. Mandriota SJ, Jussila $L$, Jeltsch $M$, et al. Vascular endothelial growth factor-C-mediated lymphangiogenesis promotes tumour metastasis. EMBO J 2001;20:672-682.

34. Karpanen T, Egeblad M, Karkkainen MJ, et al. Vascular endothelial growth factor C promotes tumor lymphangiogenesis and intralymphatic tumor growth. Cancer Res 2001;61:1786-1790.

35. Rinderknecht M, Detmar M. Molecular mechanisms of lymph node metastasisis. In: Stacker SA, Achen MG (eds). Lymphangiogenesis in Cancer Metastasis, Vol. 13. Berlin, Germany: Springer Science Business Media BV, 2009, pp 55-82.

36. Schietroma C, Cianfarani F, Lacal PM, et al. Vascular endothelial growth factor-C expression correlates with lymph node localization of human melanoma metastases. Cancer 2003;4:789-797.

37. Albrecht I, Christofori G. Molecular mechanisms of lymphangiogenesis in development and cancer. Int J Dev Biol 2011;55:483-494.

38. Cueni LN, Detmar M. The lymphatic system in health and disease. Lymphat Res Biol 2008;6:109-122.

39. Dadras SS, Paul T, Bertoncini J, et al. Tumor lymphangiogenesis: a novel prognostic indicator for cutaneous melanoma metastasis and survival. Am J Pathol 2003;6:1951-1960.

40. Nisato RE, Harrison JA, Buser R, et al. Generation and characterization of telomerase-transfected human lymphatic endothelial cells with an extended life span. Am J Pathol 2004;1:11-24.

41. Knowles $L M$, Axelrod F, Browne CD, et al. A fatty acid synthase blockade induces tumor cell-cycle arrest by down-regulating Skp2. J Biol Chem 2004;29:30540-30545.

42. Detry B, Erpicum C, Paupert J, et al. Matrix metalloproteinase-2 governs lymphatic vessel formation as an interstitial collagenase. Blood 2012;21:5048-5056.

43. Bruyère $F$, Melen-Lamalle $L$, Blacher $S$, et al. Modeling lymphangiogenesis in a three-dimensional culture system. Nat Methods 2008;5:431-437.
44. Hoshida T, Isaka N, Hagendoorn J, et al. Imaging steps of lymphatic metastasis reveals that vascular endothelial growth factor- $C$ increases metastasis by increasing delivery of cancer cells to lymph nodes: therapeutic implications. Cancer Res 2006;16:8065-8075.

45. Prophet EB, Mills B, Arrington JB et al. Laboratory methods in histotechnology. In: Johnson FB (ed). Lipids. American Registry of Pathology: Washington, DC, 1992, p 177.

46. Pizer ES, Chrest FJ, Digiuseppe JA, et al. Pharmacological inhibitors of mammalian fatty acid synthase suppress DNA replication and induce apoptosis in tumor cell lines. Cancer Res 1998;58:4611-4615.

47. Li JN, Gorospe M, Cherst FJ, et al. Pharmacological inhibition of fatty acid synthase activity produces both cytostatic and citotoxic effects modulated by p53. Cancer Res 2001;4:1493-1499.

48. Zhou W, Simpson PJ, McFadden JM, et al. Fatty acid synthase inhibition triggers apoptosis during $\mathrm{S}$ phase in human cancer cells. Cancer Res 2003;21:7330-7337.

49. Weiss L, Hoffmann GE, Schreiber R, et al. Fatty-acid biosynthesis in man, a pathway of minor importance. Purification, optimal assay conditions, and organ distribution of fatty-acid synthase. Biol Chem 1986;367:905-912.

50. Kuhajda FP. Fatty-acid Synthase and human cancer: new perspectives on its role in tumor biology. Nutrition 2000;16:202-208.

51. Seguin F, Carvalho MA, Bastos DC, et al. The fatty acid synthase inhibitor orlistat reduces experimental metastases and angiogenesis in B16-F10 melanomas. Br J Cancer 2012;6:977-987.

52. Almeida JP, Coletta RD, Silva S, et al. The proliferation of fibroblasts cultured from normal gingiva and hereditary gingival fibromatosis is dependent on fatty acid synthase activity. J Periodontol 2005;2: 272-278.

53. Jain RK, Fenton BT. Intratumoral lymphatic vessels: a case of mistaken identity or malfunction? J. Natl. Cancer Inst 2002;94:417-421.

54. Nathanson SD. Insights into the mechanisms of lymph node metastasis. Cancer 2003;98:413-423.

55. Thiele W, Sleeman J P. Tumor-induced lymphangiogenesis: a target for cancer therapy? J Biotechnol 2006;124:224-241.

56. Agostini M, Almeida LY, Bastos DC, et al. The fatty acid synthase inhibitor orlistat reduces the growth and metastasis of orthotopic tongue oral squamous cell carcinomas. Mol Cancer Ther 2014;13: 585-595.

57. Zaytseva YY, Elliott VA, Rychahou PM, et al. Cancer cell-associated fatty acid synthase activates endothelial cells and promotes angiogenesis in colorectal cancer. Carcinogenesis 2014;35:1341-1351.

58. Menendez JA, Vellon L, Oza BP, et al. Does endogenous fatty acid metabolism allow cancer cells to sense hypoxia and mediate hypoxic vasodilatation? Characterization of a novel molecular connection between fatty acid synthase (FAS) and hypoxia-inducible factor-1alpha (HIF-1alpha)-related expre. J. Cell. Biochem 2005;94:857-863.

59. Nilsson I, Rolny C, Wu Y, et al. Vascular endothelial growth factor receptor-3 in hypoxia-induced vascular development. FASEB J 2004;18: 1507-1515.

60. Teng X, Li D, Johns RA. Hypoxia up-regulates mouse vascular endothelial growth factor $D$ promoter activity in rat pulmonary microvascular smooth-muscle cells. Chest 2002;121:82-83.

61. Chaudary N, Milosevic M, Hill RP. Suppression of vascular endothelial growth factor receptor 3 (VEGFR3) and vascular endothelial growth factor C (VEGFC) inhibits hypoxia-induced lymph node metastases in cervix cancer. Gynecol Oncol 2011;123:393-400.

62. Currie MJ, Hanrahan V, Gunningham SP, et al. Expression of vascular endothelial growth factor $D$ is associated with hypoxia inducible factor (HIF-1alpha) and the HIF-1alpha target gene DEC1, but not lymph node metastasis in primary human breast carcinomas. J Clin Pathol 2004;57:829-834

63. Sounni NE, Cimino J, Blacher $\mathrm{S}$, et al. Blocking lipid synthesis overcomes tumor regrowth and metastasis after antiangiogenic therapy withdrawal. Cell Metab 2014;20:280-294.

64. Doherty GJ, McMahon HT. Mediation, modulation, and consequences of membrane-cytoskeleton interactions. Annu Rev Biophys 2008;37:65-95.

65. Hawkins PT, Anderson KE, Davidson K, et al. Signalling through Class I PI3Ks in mammalian cells. Biochem Soc Trans 2006;34:647-662.

66. Swinnen JV, Van Veldhoven PP, Timmermans L et al. Fatty acid synthase drives the synthesis of phospholipids partitioning into detergent-resistant membrane microdomains. Biochem Biophys Res Commun 2003;302:898-903. 